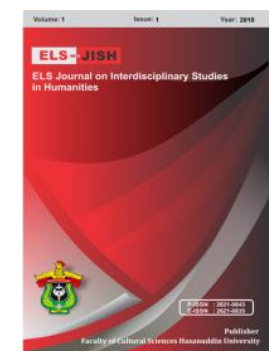

ELS-JISH

ELS Journal on Interdisciplinary Studies on Humanities

Volume 1 Issue 1, 2018

ISSN (print) : 2621-0843

ISSN (online) : 2621-0835

Homepage : http://journal.unhas.ac.id/index.php/jish

\title{
Dixon's Sit Subtype of Rest Verbs in English and Buginese
}

\author{
A. Reskiana Hartari ${ }^{1 *}$, Abdul Hakim Yassi ${ }^{2}$, Sukmawaty ${ }^{3}$ \\ *e-mail of Corresponding Author: reskihartari@gmail.com
}

\begin{abstract}
Sit Subtype refers to a stance of resting, some verbs specification of Locus is obligator and other it is optional. The aims of this research were (1) To identify Rest verbs in English and Buginese based on the Sit subtypes divided by Dixon. (2) To investigate the differences and similarities in terms of semantical and grammatical construction of Sit subtypes of Rest verbs in English and Buginese. English data were collected from Corpus of Contemporary American English (COCA), while data of Buginese were obtained from field research through process of observation and in depth interview. Both of the data were analyzed with description and qualitative analysis. The result of this research shows that (1) There are nine rest verbs of Sit subtype in English, they are sit (down), stand (up), lie (down), kneel, crouch, squat, lean, hang (down), and float, while in Buginese, there nineteen of Sit subtype: ttudang, ccado', sEppo', massampiang, massulekka, makkaddao uttu, mattulak sadang, mappasilojo', mappalempu, tettong, IIEu, maggalelu, mattojang, makkaluttu, ccuku', rroko', maccekkeng, ssanrE', maggattung, and mmawang. (2) The main differences of rest verbs in English and Buginese based on Sit subtype can be seen from two aspects, clause structure and a stance of resting. From clause structure, In English a NP is followed by VP, while in Buginese is permissible that VP is followed by NP that marked by suffix -I in VP. From a stance of resting aspect, cultural background plays important role determining the variants of the rest verb.
\end{abstract}

Keywords: Rest Verbs, Semantic Types Of Verb, Preposition, Locus, Culture

How to cite: Hartari, A. R., et al. (2018). Dixon's Sit Subtype Of Rest Verbs In English and Buginese. ELSJournal on Interdisciplinary Studies in Humanities, V(I), 21-27.

\section{Introduction}

A language is a systematic means of communication with a set of rules known as grammar. By combining words in structured and conventional way to create meaning, a particular group of people in a particular country can communicate and express themselves well to others, either spoken or written. It is also a system for delivering ideas and feelings using sounds, gestures and signs or marks

According to Greenbaum (2002), Grammar is the central component of language. It mediates between the system of sounds or of written symbols and the system of meaning. Besides, according to Griffiths (2006), say that the branch of linguistic study related to the meaning is Semantics.

Dealing with the relationship between grammar and Semantics, Dixon (2005) assumes that when speaker meet a new word the first thing happens is they will learn the meaning of the word and then they will have a comprehension to the morphological and

\footnotetext{
${ }^{1,2,3}$ Faculty of Cultural Sciences, Hasanuddin University 
syntactical form of the word. Another possibility is the speakers will learn the grammatical properties of the word then understanding its meaning.

Semantics is concerned with the system of meanings in the language, both the meanings of words and the meanings of larger units.

Therefore, the researcher wants to take research of rest verbs based on Sit Subtype in Buginese. The reason for conducting research is based on the preliminary research that there are difference meanings of rest verb in Buginese. For example, in rest verbs based on Sit subtype have nineteen verbs based on the semantics meaning.

\section{Review of Literature}

There are some brief outlines of previous studies which are related to the current study, such as Firstly, Lukman (1994) who conducted research about the Soppeng Buginese verb phrase applied a generative transformational analysis. The aim of this research is to describe the syntactic structure of the Buginese language in general and the structure of the verb phrase in particular. The result of his research is there are three types of transformation are found in Buginese verb phrases, namely an obligatory absolute maker transformation and optional intensifying and interrogative transformations. Secondly, Melansari (2015) conducted the research about Motion Verbs in English and Wolio language. This research aimed to (1) identify motion verbs in English and Wolio language and (2) investigate how the motion verbs of both English and Wolio languages differ in their meanings that accordingly affect their grammatical properties. The result of this study shows that there have been eighty two motion verbs in English and eighty five motion verbs in Wolio identified. Motion verbs in English and Wolio are not always similar in meanings, sometimes there is a slight difference or even significant difference. The main difference is some verbs of Wolio "Carry" subtype imply the specification of Locus of human's body part involved into their meanings while verbs of English "Carry" subtype generally state them after the object. Additionally, a special phenomenon occurs in Wolio motion verbs in which some verbs need "lingka" from "Arrive' subtype and "bawa" from "Take" subtype to indicate 'movement to a definite Locus' and to assert the meaning of preposition "yi" correspond to "to". Thirdly, Fahruddin (2015) in his thesis about "The Affect Verbs Subtype in English and Buginese Language: Semantic and Syntactic Approach" used descriptive qualitative method and found that English and Buginese affect verbs have equivalence and differences. Cultural background plays important role determining the variants of the verb. It can be seen in Buginese "stab" subtype (a pointed or bladed tool penetrating below the surface target) that has more variant than English "stab" subtype. New feature of "stretch" subtype (the Agent using a Manip to change the shape or state of a target) that is Agent using manip to change the taste of the Target. Buginese verbs included in this new feature are feejjei (put salt in), fissingi (put monosodium glutamate in), santangi (put coconut milk in), fellegi (put candle nut in) and cempai (put tamarin in). Lastly, Apreliah (2016) conducted Dixon's Carry Subtype of Motion verbs in English and Barru Buginese use descriptive and qualitative analysis and found there are four motion verbs of Carry subtype in English namely carry, bear, cart and transport, while in Buginese there are thirteen motion verbs of carry subtype that are mattiwi, massoppo,, majjujung, maddenge, magepa, makkaleppi, matteteng, mabbiccang, marrenreng, mallempa, matteke, maggandeng, and magule. The caluse structure, Buginese is similar with English in which noun phrase is followed by a verb phrase since all the verbs of Carry subtype is in transitive construction. In preposition aspect, Buginese have two prepositions with similar meaning but different usage, they are ri and ku which mean in. most of the Buginese 
motion verb reflect activity of the body and the preposition showed the non moving locus.

The method is written descriptively and should describe the research methodology or steps in conducting the study. A brief justification of the method is recommended to give an idea to the reader about the appropriateness of the method, reliability and validity of the results.

\section{Method}

This researcher used descriptive qualitative method in which the writer analyzed the data to compare between Rest verbs in English and Buginese, both in meaning aspect and in grammatical construction. Rest verbs in both languages were presented descriptively in the form of comparison. This research was in form of field and library research. In collecting data, first the writer listed English verbs and Buginese verbs which indicate Rest. Then the example of the verb usage of English and Buginese was obtained in different ways. English data was collected from Corpus of Contemporary American English (COCA), meanwhile Buginese data was gained from observation and in dept interview with people using Buginese data. Observation is a process of watching and memorizing the things happened around. Participant observation is a qualitative method with roots in traditional ethnographic research, whose objective is to help researchers learn the perspectives held by study populations. The Buginese data was collected from people using Buginese in kabupaten Bulukumba. The writer chooses KabupatenBulukumba because she can understand well the typical Buginese language there and it makes her get easier to collect the data. In analyzing of the data, the writer used some techniques of analyzing data in order to answer the research questions. They are: 1 . The data which had been collected were transcribed. The first step was transcribing Buginese data gained from observation and depth interview. Since English data were obtained from COCA it did not need to be transcribed anymore. 2. The numbers of transcribed data were reduced by selecting the important and related data. Both English and Buginese data which have been collected were reduced by selecting data that could be representative of others. 3 . The reduced data was presented. The next step was presenting the data. The data which had been reduced were presented based on Sit subtype divided by Dixon. Presentation of example of each rest verb was in the form of clause. English rest verbs came first and followed by Buginese rest verbs. 4. The data were then analyzed. The presented data were analyzed by applying Dixon's semantic principles, but in advance each clause was analyzed based on the word classes and semantic role. The writer used Oxford Dictionary to determine the meaning of English Rest verbs, whereas the meanings of Rest verbs in Buginese concluded based on the reading the context. The last, the writer resolved the grammatical properties of those rest verbs underlain on their meanings as the starting point. 5. Conclusion was made. After doing the analysis, in the last step the writer made some conclusions which could reflect the main points of the analysis as the result of the study.

\section{Findings}

In Buginese, there are nineteen verbs that refers to rest verb, they are ttudang, ccado', sEppo', massampiang, massulekka, makkaddao uttu, mattulak sadang, mappasilojo', mappalempu, tettong, Ileu, maggalelu, makkaluttu, ccuku', rroko', maccekkeng, ssanrE', maggattung, and mmawang. 


\subsection{Rest Verbs of Sit Subtype in English and Buginese Based on Componential Analysis and Grammatical construction}

Sit means be in a position in which one's weight is supported by one's buttocks rather than one's feet and one's back is upright. Based on the componential analysis sit verb on features is binary [+/-] on the features of chair, bench, floor, mat, ground, and bed. In Buginese, there are nine verbs which are similar to sit verb. They are ttudang, ccado', sEppo', massampiang, massulekka, mappalempu, mappasilojo, makkaddao uttu and mattulak sadang ttudang. Verb Ttudang in Buginese tends to more polite in its meaning while verb ccado' tends to impolite in its meaning but has similar meaning in a stance of rest which both of them are binary [+/-] it refers to sit such on the chair, bench or only on the floor, mat, ground, and etc, while sEppo' is absent [-] of features of chair, bench, bed. It means sEppo' is a stance of sitting such only on the floor, mat, ground, and bed or without chair or bench (have four feet). SEppo also almost has similar meaning with massampiang, massulekka, mappalempu, mappasilojo, makkaddao uttu and mattulak sadang which sitting without chair (have four feet). In their meaning they are only sitting on the floor, mat, ground, and etc. Massampiang, massulekka, mappalempu', mappasilojo, makkaddao uttu, and mattulak sadang are absent [-] on the features of chair, bench and present [+] on the floor, on the mat and on the ground. They are only different in a stance of resting, massampiang refers to a stance of sitting on the floor or on the mat with in groin stance, massulekka refers to a stance of sitting on the floor or mat with crossing legs, makkaddao uttu refers to a stance of sitting on the floor or mat then put arms round knees and hold them close, mattulak sadang refers to a stance of sitting on the floor or mat and one hand touch the cheek, mappalempu' refers to a stance of sitting without chair or only sit on the mat or the floor than put your legs straight the last mappasilojo' refers to a stance of sitting on the floor or mat or ground without chair or bench then your legs is straight position but a right foot is on left side or else.

Stand up has similar meaning with $s E p p o$ ' refers to an upright position, supported by one's feet. On the componential analysis stand up and sEppo' are absent [-] on the features of chair, bench and present [+] on the floor, on the mat and on the ground.

Lie down has similar meaning with IIEU and maggalelu refers be in a horizontal or resting position on a supporting surface. On the componential analysis lie down and sEppo and maggaleleu are absent [-] on the features of chair, bench and present [+] on the bed, on the floor, on the mat and on the ground but maggalelu tends to be only play in its meaning and almost doing by children.

Kneels has similar meaning with Makkaluttu that be a position in which the body is supported by a knee or the knees, as when praying or showing submission. On the componential analysis they are absent [-] on the features of chair, bench and present [+] on the bed, the floor, the mat and on the ground.

Crouch has similar meaning with ccuku' and rroko' means adopt a position where the knees are bent and the upper body is brought forward and down, typically in order to avoid detection or to defend oneself. On the componential analysis they are absent [-] on the features of chair, bench and present [+] on the floor, on the mat and on the ground.

Squat has similar meaning with maccEkkEng. They are refers to crouch or sit with one is knees bent and one is heels close to or touching one's buttocks or the back of one's things. On the componential analysis they are absent [-] on the features of chair, bench and present $[+]$ on the floor, on the mat and on the ground. 
Lean has similar meaning with ssanrE' refers to move into a sloping position or bend the body in that direction such as on the chair or wall or pillows. On the componential analysis they are absent [-] on the features of bench, floor, mat and present [+] chair and wall.

Hang down has similar meaning with maggattung means suspend or be suspended from above with the lower part dangling free. On the componential analysis they are absent [-] on the features of bench, floor, mat, chair, wall and present [+] branch.

Float has similar meaning with mmawang means rest or move on or near the surface of a liquid without sinking. On the componential analysis table that float absent [-] on the features of bench, floor, mat, chair, wall and present [+] water.

In Buginese, there are several verbs that implied the specification of locus as a place of rest into their meanings such as sEppo', massulekka, makkaddao uttu, mattulak sadang, mappasilojo', mappalempu', mmattojang, massampiang because they are clear when they are present [+] and when they are absent [-] of features. In English verb sit features such chair, bench floor, ground, and mat, is binary [+/-] it means the verb doesn't implied the specification of locus as a place of rest, this is similar to the verb ttudang and ccado' in Buginese which is also the features is binary [+/-].

\subsection{Recapitulation Buginese in Rest Verb of Sit Subtype as well as grammatical construction of Related Examples}

Ttudang or Ccado; the resting role is a predicate. Locus may be not stated because it can be inferred from the verb itself. Seppo; the resting role is a predicate. The locus is in the form of adverb marked by preposition. Massampiang; he resting role is a predicate. The locus is in the form of a adverb marked by preposition. Massulekka; the resting role is a predicate. The locus is in the form of a noun phrase marked by preposition. Makkaddao uttu; the resting role is a predicate. Locus may be not stated because it can be inferred from the verb itself. Mattulak sadang refers to sitting on the floor or ground without chair or bench then putting arms on knees and one hand touch the cheek. The resting role is a predicate. Locus may be not stated because it can be inferred from the verb itself. Mappasilojo; the resting role is a predicate. Locus may be not stated because it can be inferred from the verb itself. Mappalempu'; the resting role is a predicate. Locus may be not stated because it can be inferred from the verb itself. Lleu'; the resting role is a verb. Locus is a place of rest marked by the appropriate preposition placed after the predicate. The locus is in the form of an adverb marked by preposition. Maggalelu; the resting role is a verb. Locus is a place of rest marked by the appropriate preposition after the predicate. Makkaluttu assume that a position which the body is supported by a knee or the knees, as showing submission. The resting role is a predicate. Locus may be not stated because it can be inferred from the verb itself. Ccuku'; the resting role is a predicate. Locus may be not stated because it can be inferred from the verb itself. Rroko'; the resting role is a predicate. Locus may be not stated because it can be inferred from the verb itself. Maccekkeng; the resting role is a predicate. The locus is in the form of a noun phrase marked by preposition. Ssanre'; the resting role is a predicate. Locus may be not stated because it can be inferred from the verb itself. Maggattung; the resting role is a predicate. Locus may be not stated because it can be inferred from the verb itself. Mmawang; the resting role is a predicate. Locus may be not stated because it can be inferred from the verb itself.

In brief, Sit subtype refers to a stance of resting. Since they describe as a mode of 
rest the only obligatory role is resting. For some verbs specification of locus as a place of rest is obligatory and others is optional. When some the verbs are transitive, a noun phrase in locus role is most often marked by appropriate preposition and placed after predicate where place adverbial noun phrase subject are semantically linked to the rest verb and are typically placed after the predicate.

\section{Discussion}

Based on the Buginese data shown in finding, there are seven variations or patterns of constructions in Buginese as in the follow table:

Table 1. seven variations or patterns of constructions in Buginese.

\begin{tabular}{|c|c|c|}
\hline No & Pattern & Verb \\
\hline 1. & $\mathbf{V P}$ & Ttudang, ccado', sEppo, massulekka, tettong, crouch \\
\hline 2. & $\mathrm{VP}+\mathrm{NP}+\mathrm{ADV}$ & $\begin{array}{l}\text { Ttudang, sEppo', mappallempu, tettong, llEu', maccekkeng, ssanre', } \\
\text { mmawang }\end{array}$ \\
\hline 3. & VP+ADV & $\begin{array}{l}\text { SEppo', massampiang, massulekka, makkaddao uttu, mappalempu, } \\
\text { tettong, llEu', maggalelu, makkaluttu, ccuku', rroko', maccekkeng, } \\
\text { ssanre', maggattung, mmawang }\end{array}$ \\
\hline 4. & NP+VP+ADV & makkaddao uttu \\
\hline 5. & $\mathbf{A D V}+\mathbf{V P}$ & Mappasilojo, ttudang, ccado' \\
\hline 6. & $\mathbf{V P + N P}$ & Mattojang \\
\hline 7. & $\mathbf{V P}+\mathrm{NP}+\mathrm{VP}+\mathrm{NP}$ & Mmattulak sadang \\
\hline
\end{tabular}

From the table above shows that it is general to not begin the sentence with noun phrase (NP) as subject but with verb phrase (VP), or adverb (ADV). Most of the VP in Buginese sentence consist of prefix or suffix which reflect the subject pronoun of the sentence. They are prefix na- and nu- and suffix - $i$, -ka, -ki, -na. Prefix na- reflects the third person singular pronoun of the sentence and Prefix -nu reflects the second person singular pronoun of the sentence. While suffix -i and -na reflects third person singular pronoun of the sentence, suffix -ka reflects first singular person pronoun of the sentence, and suffix $-k i$ reflects second person pronoun of the sentence. Additionally, there two suffixes of noun phrase object which reflects possession, it is - ku which is means my and na means his/her.

\section{Conclusion}

In Buginese there are nineteen rest verbs of Sit subtype found in this research, they are ttudang, ccado', sEppo', massampiang, massulekka, makkaddao uttu, mattulak sadang, mappasilojo', mappalempu, tettong, IIEu, maggalelu, makkaluttu, ccuku', rroko', maccekkeng, ssanrE', maggattung, and mmawang. There are several verbs that implied the specification of locus as place to rest in their meanings such as sEppo', massampiang, massulekka, makkaddao uttu, mattulak sadang, mappallempu, mappasilojo, ccuku'. Also there some rest verbs could become transitive verb such as ttudang, tettong, mattojang, ssanre, maccekkeng, lleu, mmawang so it needs object noun phrase.

The meaning differences between English rest verbs of sit subtype and Buginese rest verbs because the different grammatical constructions. The main differences of rest verbs of Sit subtype in English and Buginese can be seen from two aspects, clause structure and a stance of resting. From clause structure, it can be found that basically 
clause structure of Buginese is similar with English in which it has locus as place rest and noun phrase for some verbs of Sit subtype is in transitive constructions. However, the clause structures in Buginese have some variations and can be simplified to become only a verb (or a verb phrase) as long as the subject is plainly comprehensible from the previous context. The variations of buginese clause structure are VP, VP+NP+ADV, $V P+A D V, N P+V P+A D V, A D V+V P, V P+N P$ and $V P+N P+V P+N P$. Also most of the Buginese rest verbs reflect the adverbial of locus or locus as a place of rest. Besides that, from a stance of resting there is relation with the Buginese culture. Buginese term of Sit could have several different meanings and different context like 'massulekka' used in traditional ceremony, 'ttudang ade', 'mabbaca-baca', 'ttudang sipulung' used in their rituals. Sit also could mean polite and impolite. 'massulekka' always represent politeness while 'cekkeng', 'mappasilojo' and 'mappalempu' usually represent impoliteness. The politeness always refers to nobility society, and impoliteness always refers to ordinary people. Ttudang always used by nobility and ccado' 'Sit' also could mean forbidden or taboo like makkaddao uttu' or 'mattula' sadang', and 'mappasilojo'. However, in English some of the Sit subtype are seldom or never e.g kneel, crouch, cross legs, etc because people do not often make them or they are not easy for them. Thus Dixon theory in this Sit subtype cannot be generalized into whole Buginese rest verbs referring Sit subtype.

This current study applies semantic approach to analyze grammar of language. There are some other categories that are proposed by Dixon. This current study takes one that is Sit subtype. In the future, the writer expects that there will be another researcher who takes other subtype of Dixon to analyze or applies another local language to be compared to English.

\section{References}

Apreliah, R. (2016). Dixon's Carry Subtype of motion Verbs in English and Barru Buginese (Unpublished Thesis). Post Graduate Program, Hasanuddin University, Makassar.

Dixon, R. M. W. (2005). A Semantic Approach to English Grammar. New York: Oxford University Press Inc.

Fahruddin. (2015). The Affect Verbs Subtypes In English And Buginese Language: semantical and syntactical perspective (Unpublished Thesis). Post Graduate Program, Hasanuddin University, Makassar.

Greenbaum, S, \& Nelson, G. (2002). An introduction to English grammar. United Kingdom: Graphicraft Limited.

Griffiths, P. (2006). An Introduction to English Semantics and Pragmatics. Edinburgh: Edinburgh University Press.

Lukman. (1994). The Soppeng Buginess Verb Phrase, A Generative Transformational Analysis (Unpublished Thesis). Post Graduate Program, Hasanuddin University, Makassar.

Melansari, N. (2015). Motion Verbs in English and Wolio language: A Semantic Point of View (Unpublished Thesis). Post Graduate Program, Hasanuddin University, Makassar. 